\title{
Mobile Health Coaching on Nutrition and Lifestyle Behaviors for Subfertile Couples Using the Smarter Pregnancy Program: Model-Based Cost-Effectiveness Analysis
}

Elsje C Oostingh, MD; Robbin H Ophuis, MSc; Maria PH Koster, MD, PhD; Suzanne Polinder, PhD; Hester F Lingsma, PhD; Joop SE Laven, MD, PhD; Régine PM Steegers-Theunissen, MD, PhD

Erasmus University Medical Center, Rotterdam, Netherlands

\section{Corresponding Author:}

Régine PM Steegers-Theunissen, MD, PhD

Erasmus University Medical Center

Postbus 2040

Rotterdam, 3000 CA

Netherlands

Phone: 31107038255

Email: r.steegers@erasmusmc.nl

\begin{abstract}
Background: The health care costs for reproductive care have substantially increased with the use of in vitro fertilization (IVF) treatment. The mobile health (mHealth) coaching program Smarter Pregnancy is an effective intervention to improve nutrition and lifestyle behaviors and pregnancy rates in (sub)fertile couples, including those who undergo IVF treatment. Therefore, we hypothesize that this mHealth program can also reduce health care costs associated with IVF treatment.

Objective: This study aimed to evaluate the cost-effectiveness of the mHealth coaching program Smarter Pregnancy and compare it to usual care in women of subfertile couples who start their first IVF cycle.

Methods: This model-based cost-effectiveness analysis was performed on data from couples undergoing IVF treatment at the Erasmus MC, University Medical Center Rotterdam. A decision tree model was used to assess the incremental cost-effectiveness ratio (ICER) of ongoing pregnancies and costs of use of the mHealth program as compared to usual care. A probabilistic sensitivity analysis was performed to consider the uncertainty surrounding the point estimates of the input parameters.

Results: Based on our model including 793 subfertile women undergoing IVF treatment, use of the mHealth program resulted in 86 additional pregnancies and saved $€ 270,000$ compared to usual care after two IVF cycles, with an ICER of $€ 3050$ (95\% CI -3960 to -540 ) per additional pregnancy. The largest cost saving was caused by the avoided IVF treatment costs. Sensitivity analyses showed that the mHealth program needs to increase the ongoing pregnancy rate by at least $51 \%$ after two IVF cycles for cost saving.

Conclusions: The mHealth coaching program Smarter Pregnancy is potentially cost saving for subfertile couples preceding their first IVF treatment. Implementation of this mHealth program in routine preconception care for subfertile couples should be seriously considered, given the relatively low costs and promising cost-effectiveness estimates.
\end{abstract}

(JMIR Mhealth Uhealth 2019;7(10):e13935) doi: 10.2196/13935

\section{KEYWORDS}

preconception; subfertility; IVF treatment; pregnancy; cost-effectiveness

\section{Introduction}

Since the pioneer work of Edwards and Steptoe, in vitro fertilization (IVF) has become an indelible technology in modern era. Although the ongoing pregnancy rate after IVF treatment has tremendously increased [1], subfertility remains a worldwide problem affecting approximately $12 \%$ of couples of reproductive age [2]. In addition to the medical causes of subfertility, poor nutrition and lifestyle behaviors can impair fertility as well [3]. The mobile health (mHealth) coaching program Smarter Pregnancy $[4,5]$ was developed to motivate (sub)fertile couples to adopt healthy nutrition and lifestyle behaviors. In a survey among (sub)fertile couples and a primary analysis of a randomized controlled trial (RCT) among couples with an IVF treatment indication, we showed that online coaching of 
participants resulted in significant improvements of their nutrition and lifestyle behaviors [6,7]. Moreover, our survey also showed that improvements in nutritional behavior lead to an increase in ongoing pregnancy rates in fertile and subfertile couples with and without IVF treatment [8]. The health care and societal costs of IVF treatment are substantial [9], and we believe that many costs can be saved when a healthy lifestyle is adopted. Here, we aim to assess the cost-effectiveness of the use of this mHealth program compared to usual care in subfertile women preceding their first IVF treatment.

\section{Methods}

\section{Study Population}

The data were derived from a modelled study population consisting of subfertile women undergoing their first IVF treatment at the Erasmus MC, University Medical Center Rotterdam, the Netherlands. The data of the RCT were used to model nutrition and lifestyle behaviors. In this RCT, participants were randomly assigned to the intervention or control group. Participants of the intervention group received the complete coaching program and were coached on a maximum of five nutrition and lifestyle behaviors: vegetable, fruit, and folic acid supplement intake, smoking, and alcohol consumption. Participants of the control group only received a diminished version of the program. At several time points, all participants were asked to fill out questionnaires about their nutrition and lifestyle behavior. In this way, change in behavior could be measured. Participants of the RCT started the program at a maximum of 2 months before start of their IVF treatment, and the program lasted for a period of 24 weeks (Figure 1). The study protocol and primary results of the RCT on the improvement of these behaviors have been published elsewhere $[6,10]$. In brief, participants in the intervention group showed a significantly larger improvement in inadequate behavior compared to the control group [6].

Figure 1. Overview of both the intervention and control groups during their enrollment in the Smarter Pregnancy randomized controlled trial. Adapted from van Dijk et al [<xref ref-type="bibr" rid="ref10">10</xref>]. SMS: short message service.

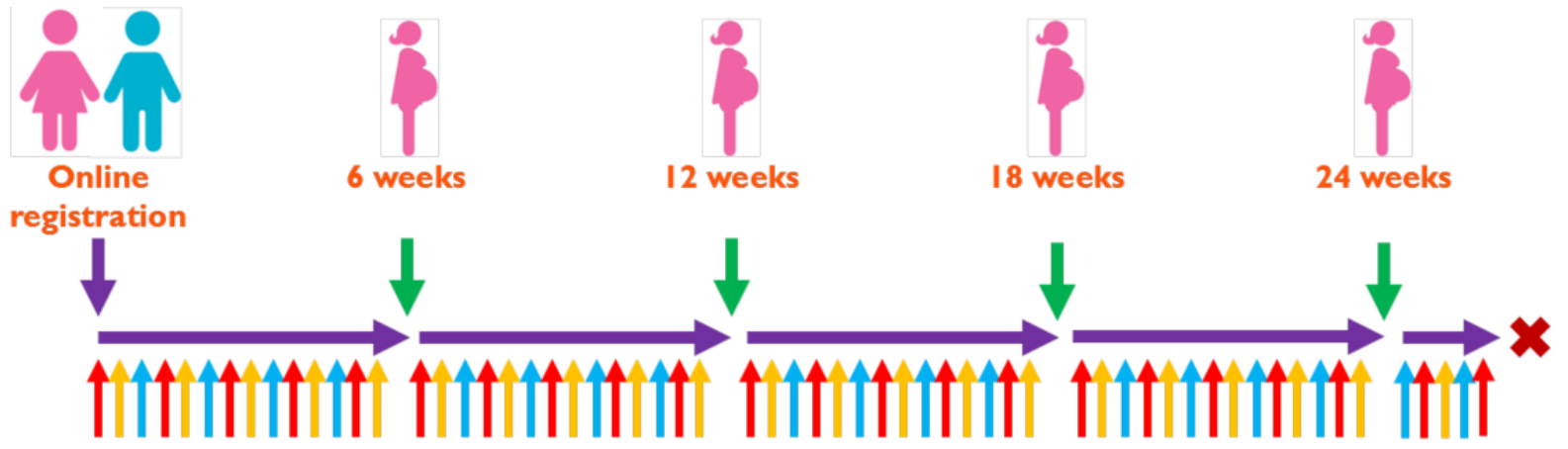

Legend

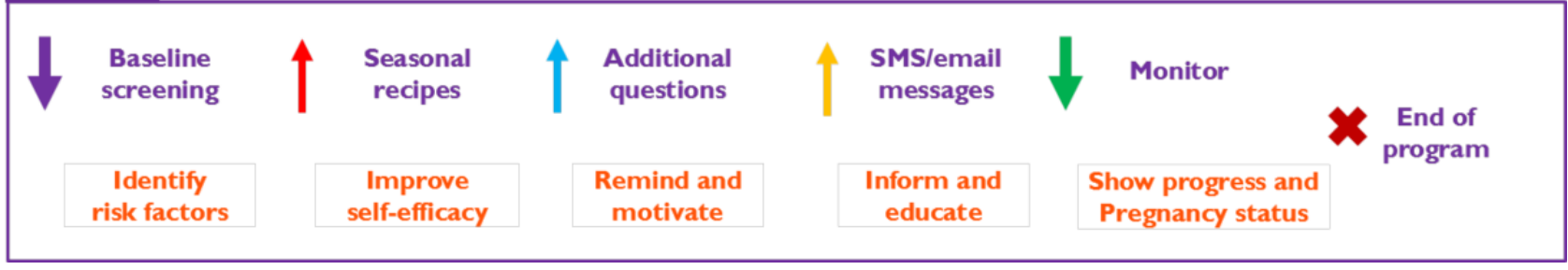

\section{Model}

A decision tree model was constructed using Microsoft Excel (version 2010; Microsoft Corporation, Redmond, Washington) to assess the incremental ongoing pregnancies following the first IVF cycle and the costs of the mHealth program as compared to usual care (Figure 2). Ongoing pregnancy was defined as a vital pregnancy at 12 weeks of gestation. Women of subfertile couples who underwent their first IVF treatment in 2015 entered the model $(n=793)$. A second IVF cycle was started if the first cycle did not result in an ongoing pregnancy. Pregnancy outcome following the second IVF cycle was the endpoint of the model. This short-term evaluation should therefore be considered a first indication of cost-effectiveness of the mHealth program. 
Figure 2. Decision tree model. IVF: in vitro fertilization.

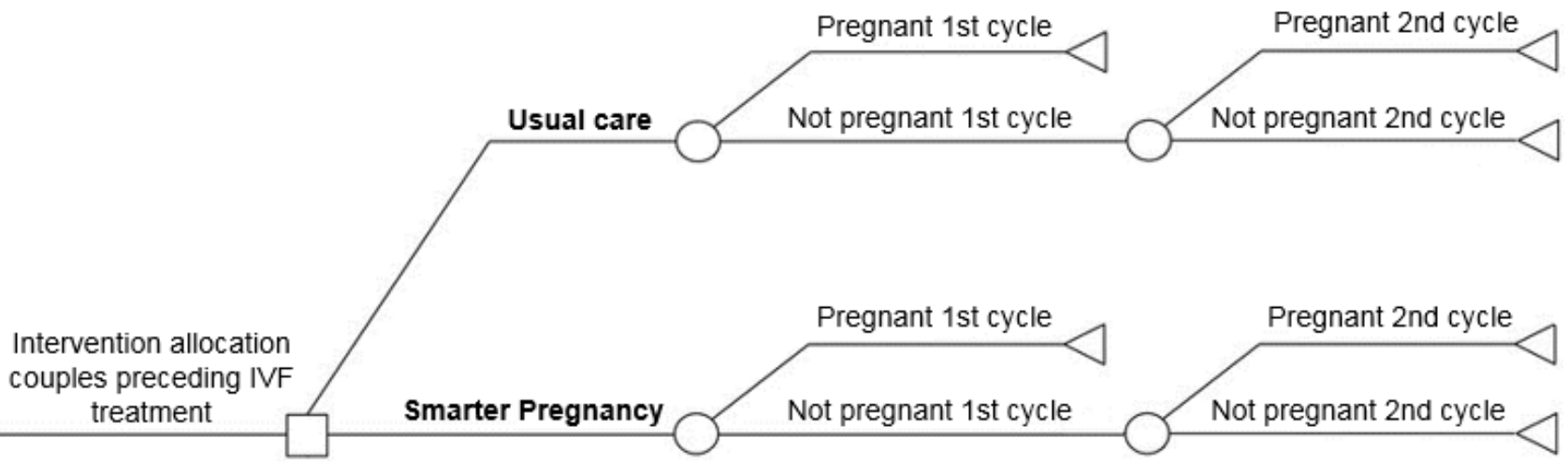

\section{Model Scenarios}

The usual care scenario reflects usual IVF treatment in the Netherlands. We assumed that all women received an elective single embryo transfer and that pregnancy rates in usual care are $33 \%$ for the first IVF cycle and $23 \%$ for the second cycle [11]. We furthermore assumed that all women in the intervention scenario were offered the mHealth program (100\% coverage). This program was not offered in the usual care scenario $(0 \%$ coverage). The intervention adherence rate was set at $70 \%$, based on RCT data in which $70 \%$ of participants in the intervention group completed the coaching [6].

\section{Model Parameters}

Analyses were performed from a health care and societal perspective. The health care perspective includes costs related to the mHealth program [12], all costs associated with IVF treatment (eg, laboratory and hospital costs), and other relevant health care costs (eg, general practitioner visits). The societal perspective includes all health care costs plus costs outside the health care sector (eg, costs due to absence at work). The model parameters, including their distributions and sources, are reported in Table 1. Ongoing pregnancy rates after the first and second IVF cycle for the Smarter Pregnancy scenario and the usual care scenario were based on our previous study in the same setting [8] and others [13]. A detailed description of the cost calculations has been provided by Fiddelers et al [9]. All costs were expressed in euros $(€)$ for the reference year 2016 based on the Dutch price index [14]. 
Table 1. Model input parameters.

\begin{tabular}{|c|c|c|c|}
\hline Input parameter & Deterministic value & Probabilistic distribution & Source \\
\hline \multicolumn{4}{|l|}{ IVF $^{\mathrm{a}}$ costs (per cycle), $€$} \\
\hline \multicolumn{4}{|l|}{ Hospital costs } \\
\hline Hormone stimulation - medication & 1580 & Fixed & Fiddelers et al [9] \\
\hline Hormone stimulation - hospital care & 331 & Fixed & Fiddelers et al [9] \\
\hline Ovum pick-up & 596 & Fixed & Fiddelers et al [9] \\
\hline Lab & 1339 & Fixed & Fiddelers et al [9] \\
\hline Embryo transfer & 316 & Fixed & Fiddelers et al [9] \\
\hline Other & 295 & Gamma & Fiddelers et al [9] \\
\hline \multicolumn{4}{|l|}{ Other health care costs } \\
\hline General practitioner & 3 & Gamma & Fiddelers et al [9] \\
\hline Other & 13 & Gamma & Fiddelers et al [9] \\
\hline \multicolumn{4}{|l|}{ Costs outside health care ${ }^{b}$} \\
\hline Sick leave & 569 & Gamma & Fiddelers et al [9] \\
\hline Leave of absence & 141 & & Fiddelers et al [9] \\
\hline Loss of leisure time & 73 & Gamma & Fiddelers et al [9] \\
\hline Out of pocket expenditures & 77 & Gamma & Fiddelers et al [9] \\
\hline Informal care & 32 & Gamma & Fiddelers et al [9] \\
\hline Other & 22 & Gamma & Fiddelers et al [9] \\
\hline \multicolumn{4}{|l|}{ Intervention costs, $€$} \\
\hline Smarter Pregnancy program costs & $61^{\mathrm{c}}$ & Gamma & Luyendijk [12] \\
\hline \multicolumn{4}{|l|}{ Lifestyle costs ${ }^{b}, €$} \\
\hline Folic acid supplement use & 64 & Fixed & Luyendijk [12] \\
\hline Healthy nutrition & 113 & Fixed & Luyendijk [12] \\
\hline Smoking & 1,223 & Fixed & Based on data from [15] and [16] \\
\hline Alcohol consumption & 913 & Fixed & Based on data from [17] and [18] \\
\hline \multicolumn{4}{|l|}{ Pregnancy rates usual care } \\
\hline First IVF cycle & 0.329 & Beta & Based on Wade et al [11] \\
\hline Second IVF cycle & 0.229 & Beta & Based on Wade et al [11] \\
\hline \multicolumn{4}{|l|}{ Pregnancy rate intervention } \\
\hline First IVF cycle - $65 \%$ increase & 0.543 & Beta & Based on Twigt et al [8] \\
\hline Second IVF cycle $-65 \%$ increase & 0.443 & Beta & Based on Twigt et al [8] \\
\hline
\end{tabular}

${ }^{\mathrm{a}} \mathrm{IVF}$ : in vitro fertilization.

${ }^{\mathrm{b}}$ Only included in the analysis from a societal perspective. We assumed that the participants who smoke use 10 cigarettes per day (average daily use of smokers in the Netherlands) and that alcohol consumers drink one alcoholic beverage per day.

${ }^{c}$ Based on the annual tariff. This is considered to be an indication for the actual costs, which mainly consist of maintenance, insurance, overhead, and text messages.

\section{Cost-Effectiveness Analysis}

The primary effect outcome measure was expressed as the number of ongoing pregnancies after two IVF cycles. Incremental cost-effectiveness ratios (ICERs) from health care and societal perspectives were calculated by dividing the difference in costs between the Smarter Pregnancy scenario and the usual care scenario by the difference in the number of ongoing pregnancies in both scenarios. The ICER represents the estimated costs of one additional ongoing pregnancy.

A probabilistic sensitivity analysis was performed to consider the uncertainty surrounding the point estimates of the model input parameters. Probabilistic distributions were assigned to the parameters (Table 1). Thereafter, 1000 model iterations were performed by drawing random values from the distributions 
assigned to the input parameters. We calculated the average costs and ongoing pregnancies by averaging these 1000 iterations. We performed deterministic sensitivity analyses to investigate the impact of changing several key parameters of the model: the coverage and adherence rate of the mHealth program and the chance of an ongoing pregnancy following the use of this program.

\section{Results}

Based on our model including 793 women, the mHealth scenario resulted in 369 pregnancies (47\%; 95\% CI 317-422) and the usual care scenario resulted in 283 pregnancies $(36 \%$; $95 \% \mathrm{CI}$ 209-363) after two IVF cycles (Figure 1). The average health care costs for the mHealth and the usual care scenario were $€ 6,008,500(95 \%$ CI 5,671,000-6,505,000) and €6,214,800 (95\% CI 5,839,500-6,730,300), respectively. The average societal costs for the mHealth and the usual care scenarios were
$€ 7,492,400$ (95\%CI $6,821,300 ; 8,369,400)$ and $€ 7,762,400$ (95\%CI 7,008,500-8,716,800), respectively (Figure 3). The ICERs from health care and societal perspectives per additional ongoing pregnancy equaled $-€ 2250$ (95\% CI -3030 to -760 ) and $-€ 3050$ (95\% CI -3960 to -540 ), respectively. Figure 4 shows that almost all ICERs are located in the southeast quadrant of the cost-effectiveness plane, indicating that the use of the mHealth program is cost saving.

The sensitivity analyses (Table 2) showed that the mHealth program is cost saving, on an average, but the uncertainty surrounding the ICERs increases when the intervention is less effective due to a lower compliance and ongoing pregnancy rate. For example, use of the mHealth program should increase the ongoing pregnancy rate by at least $51 \%$ for it to be cost saving compared to usual care when a $70 \%$ adherence rate is assumed. Otherwise, given an increased pregnancy rate of $65 \%$, the compliance to Smarter Pregnancy should be at least $49 \%$ for it to remain cost saving.

Figure 3. Costs and effects (ongoing pregnancy rate) of the mobile health coaching program Smarter Pregnancy (intervention) and usual care, categorized as per health care and societal perspectives.

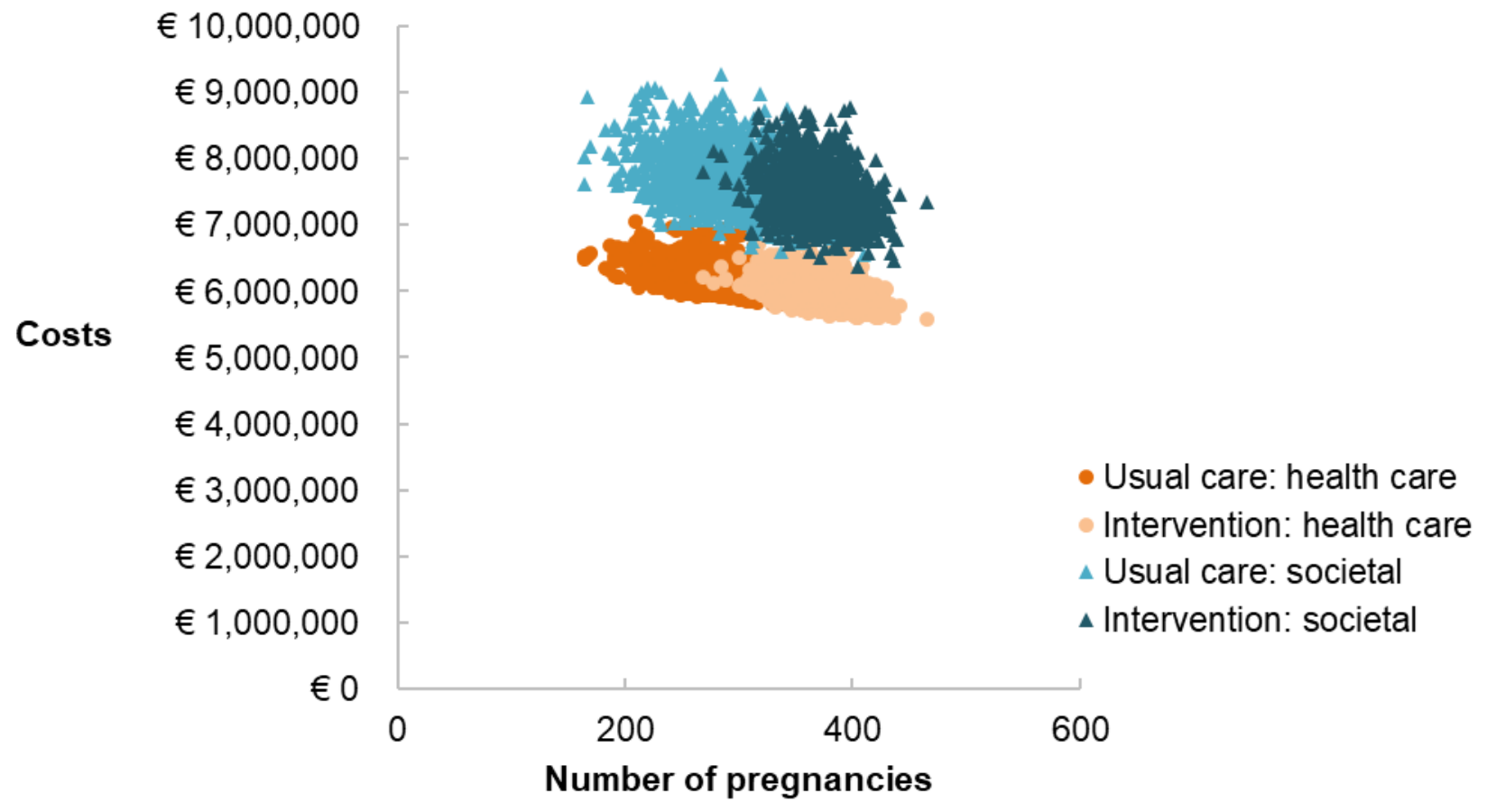


Figure 4. Incremental cost-effectiveness ratios generated by 1000 model simulations, categorized as per health care and societal perspectives.

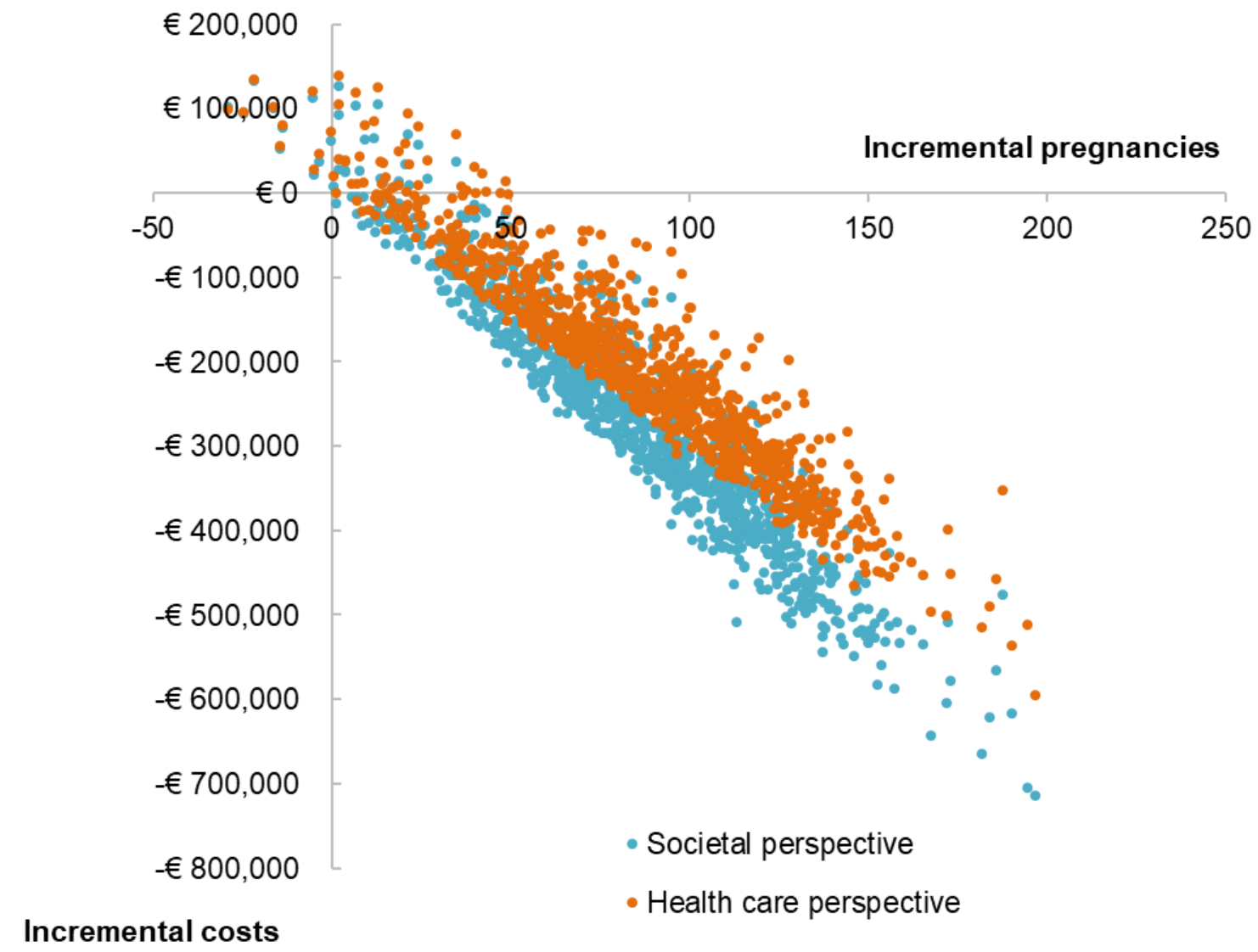

Table 2. Results of the sensitivity analyses.

\begin{tabular}{|c|c|c|c|}
\hline Result & $\begin{array}{l}\text { Mean number of incremental } \\
\text { pregnancies }\end{array}$ & Mean incremental societal costs, $€$ & $\begin{array}{l}\text { Mean ICER }{ }^{\mathrm{a}} \text { societal perspective } \\
(95 \% \mathrm{CI}), €\end{array}$ \\
\hline Main analysis ${ }^{b}$ & 86 & $-270,000$ & $-3050(-3960$ to -540$)$ \\
\hline \multicolumn{4}{|l|}{ Sensitivity analyses } \\
\hline $85 \%$ intervention compliance & 105 & $-340,200$ & $-3210(-3960$ to -1630$)$ \\
\hline $55 \%$ intervention compliance & 63 & $-192,000$ & $-2840(-3920$ to -120$)$ \\
\hline $45 \%$ increase in pregnancy rate $(0.477)$ & 64 & $-186,300$ & $-3070(-5610$ to 1620$)$ \\
\hline $25 \%$ increase in pregnancy rate $(0.411)$ & 40 & $-98,300$ & $-2300(-9610$ to 9520$)$ \\
\hline $70 \%$ intervention coverage & 62 & $-187,600$ & $-2840(-3930$ to -540$)$ \\
\hline $\begin{array}{l}85 \% \text { intervention } \\
\text { coverage }\end{array}$ & 74 & $-227,400$ & $-2850(-3900$ to -710$)$ \\
\hline Worst-case scenario $^{c}$ & 21 & $-37,300$ & $-1270(-20,900$ to 13,200$)$ \\
\hline Best-case scenario $^{\mathrm{d}}$ & 123 & $-408,900$ & $-3600(-3900$ to -1850$)$ \\
\hline
\end{tabular}

${ }^{a}$ ICER: incremental cost-effectiveness ratio.

${ }^{b} 100 \%$ intervention coverage, $70 \%$ intervention compliance, $65 \%$ increase in pregnancy rate.

${ }^{\mathrm{c}} 70 \%$ intervention coverage, $55 \%$ intervention compliance, $25 \%$ increase in pregnancy rate.

${ }^{d} 100 \%$ intervention coverage, $100 \%$ intervention compliance, $65 \%$ increase in pregnancy rate. 


\section{Discussion}

\section{Principal Findings}

This model-based study, determining the estimates of available data, showed that the use of the mHealth program would result in 86 additional pregnancies and a reduction of $€ 270,000$ compared to usual care after two IVF cycles, resulting in an ICER of $-€ 3050$ per additional ongoing pregnancy. Sensitivity analyses showed that the use of this mHealth program is cost saving when the ongoing pregnancy rate increases to at least $51 \%$ after two cycles of single embryo-transfer IVF treatment.

\section{Strengths and Limitations}

A strength of our model is the combined use of evidence-based data of the population, clinical effectiveness, compliance, and costs to support decision making. Although model parameters would ideally be based on meta-analyses or larger datasets, these were unavailable. Since the Smarter Pregnancy RCT is ongoing, assumptions regarding ongoing pregnancy rates had to be made based on our previous data. In economic evaluations, a time horizon that is long enough to capture all relevant costs and effects is preferred [19]. Our study was limited to two IVF cycles, which may be relatively short. However, as the endpoint of our study was to assess the incremental ongoing pregnancy rate, other costs and long-term reproductive and health outcomes were not considered.

We evaluated single embryo transfers only, because in the Netherlands, this is the most common IVF strategy. Therefore, costs and ongoing pregnancy rates of other IVF strategies will be different [13].

\section{Comparison With Prior Work}

Several studies have investigated the effectiveness of nutrition and lifestyle interventions preceding fertility treatment. However, most of these studies focus on specific patient groups such as obese or anovulatory women [20,21]. In accordance with our findings, the study by Van Oers et al [22] showed that lifestyle intervention preceding fertility treatment was cost-effective in terms of achieving an ongoing pregnancy within 24 months.

The difference in average societal costs and health care costs was relatively small, indicating that the addition of the non-healthcare costs had no substantial impact on the ICER. Because nutrition and lifestyle interventions in preconception care have relatively low additional budget impact, we expect that the chance that the mHealth program is not cost-effective would be low [23].

\section{Conclusions}

Our results show that the mHealth coaching program Smarter Pregnancy is potentially cost saving for subfertile couples preceding their first IVF treatment. Although our results are promising, our model requires further validation based on actual data on ongoing pregnancy rates from the Smarter Pregnancy RCT in order to establish the relative cost-effectiveness of the mHealth program with greater certainty. Implementation of this mHealth program in routine preconception care of subfertile couples should be seriously considered, given the relatively low intervention costs and promising cost-effectiveness estimates.

\section{Acknowledgments}

This study was funded by a grant from ZonMW; the Netherlands Organization for Health Research and Development (project number 209040003), and the Department of Obstetrics and Gynecology of the Erasmus MC, University Medical Center, Rotterdam, the Netherlands. The sponsor had no role in the analysis or preparation of the manuscript.

\section{Conflicts of Interest}

RS-T is CEO of eHealth Care Solutions (since 2013). JL has received grants from Ferring BV, Dutch Heart Association, ZonMw, Danone, Euroscreen, Anshlabs, and Titus Healthcare outside the submitted work. No other disclosures are reported.

\section{References}

1. Kushnir VA, Barad DH, Albertini DF, Darmon SK, Gleicher N. Systematic review of worldwide trends in assisted reproductive technology 2004-2013. Reprod Biol Endocrinol 2017 Jan 10;15(1):6 [FREE Full text] [doi: 10.1186/s12958-016-0225-2] [Medline: 28069012]

2. Inhorn MC, Patrizio P. Infertility around the globe: new thinking on gender, reproductive technologies and global movements in the 21st century. Hum Reprod Update 2015;21(4):411-426 [FREE Full text] [doi: 10.1093/humupd/dmv016] [Medline: 25801630]

3. Homan GF, Davies M, Norman R. The impact of lifestyle factors on reproductive performance in the general population and those undergoing infertility treatment: a review. Hum Reprod Update 2007;13(3):209-223. [doi: 10.1093/humupd/dml056] [Medline: 17208948]

4. Smarter Pregnancy: Personal coaching for healthy food- and lifestyle habits. URL: https://www.smarterpregnancy.co.uk/ $\underline{\text { research/ [accessed 2018-12-29] [WebCite Cache ID 751h3BVP3] }}$

5. Slimmer Zwanger: Persoonlijke coaching voor gezonde voedings- en leefstijlgewoonten. URL: https://www. slimmerzwangeronderzoek.nl/nl/ [accessed 2018-12-29] [WebCite Cache ID 751hektYe] 
6. Oostingh E, Koster M, van Dijk M, Willemsen S, Steegers E, Laven J. Improvement of Periconception nutrition and lifestyle behaviors using the mHealth program: a randomized controlled trial. 2018 Mar 25 Presented at: Society for Reproductive Investigation; March 25, 2018; Orlando p. 2018.

7. Van Dijk MR, Huijgen NA, Willemsen SP, Laven JS, Steegers EA, Steegers-Theunissen RP. Impact of an mHealth Platform for Pregnancy on Nutrition and Lifestyle of the Reproductive Population: A Survey. JMIR Mhealth Uhealth 2016 May 27;4(2):e53 [FREE Full text] [doi: 10.2196/mhealth.5197] [Medline: 27234926]

8. Twigt JM, Bolhuis MEC, Steegers EAP, Hammiche F, van IWG, Laven JSE, et al. The preconception diet is associated with the chance of ongoing pregnancy in women undergoing IVF/ICSI treatment. Hum Reprod 2012 Aug;27(8):2526-2531 [FREE Full text] [doi: 10.1093/humrep/des157] [Medline: 22593431]

9. Fiddelers AAA, van Montfoort APA, Dirksen CD, Dumoulin JCM, Land JA, Dunselman GAJ, et al. Single versus double embryo transfer: cost-effectiveness analysis alongside a randomized clinical trial. Hum Reprod 2006 Aug;21(8):2090-2097. [doi: 10.1093/humrep/del112] [Medline: 16613886]

10. van Dijk MR, Oostingh EC, Koster MPH, Willemsen SP, Laven JSE, Steegers-Theunissen RPM. The use of the mHealth program Smarter Pregnancy in preconception care: rationale, study design and data collection of a randomized controlled trial. BMC Pregnancy Childbirth 2017 Jan 26;17(1):46 [FREE Full text] [doi: 10.1186/s12884-017-1228-5] [Medline: 28125970]

11. Wade JJ, MacLachlan V, Kovacs G. The success rate of IVF has significantly improved over the last decade. Aust N Z J Obstet Gynaecol 2015 Oct;55(5):473-476. [doi: 10.1111/ajo.12356] [Medline: 26174052]

12. Luyendijk M. Cost-effectiveness of an e-Health intervention to improve unhealthy lifestyle behaviors in subfertile women. 2013 Aug 22. URL: https://thesis.eur.nl/pub/15868/ [accessed 2019-09-02]

13. Fiddelers AAA, Dirksen CD, Dumoulin JCM, van Montfoort APA, Land JA, Janssen JM, et al. Cost-effectiveness of seven IVF strategies: results of a Markov decision-analytic model. Hum Reprod 2009 Jul;24(7):1648-1655. [doi:

10.1093/humrep/dep041] [Medline: 19318703]

14. Centraal Bureau voor de Statistiek. StatLine. 2017. Consumentenprijzen; prijsindex 2015=100 Gewijzigd op: 6 augustus 2019 URL: https://opendata.cbs.nl/\#/CBS/nl/dataset/83131NED/table?dl=5400 [accessed 2017-01-01] [WebCite Cache ID 751hhvT33]

15. Stichting stop bewust. Wat kost roken URL: $\underline{\text { https://ikstop.nl/wat-kost-roken [accessed 2018-12-29] [WebCite Cache ID }}$ 751hjc14L]

16. Stichting stop bewust. Roken en statistiek URL: https://ikstop.nl/roken-en-statistiek [accessed 2018-12-29] [WebCite Cache ID 751hlD86r]

17. Trimbos instituut. Cijfers alcohol URL: https://www.trimbos.nl/kerncijfers/cijfers-alcohol [accessed 2018-12-29] [WebCite Cache ID 751iCTXWQ]

18. Jellinek. Informatie over alcohol en drugs URL: https://www.jellinek.nl/informatie-over-alcohol-drugs/alcohol/ alcohol-basisinfo/soorten-en-prijzen-alcohol [accessed 2018-12-29] [WebCite Cache ID 751hoN05p]

19. Briggs A, Sculpher M, Claxton K. Decision modelling for health economic evaluation. Oxford, UK: Oxford University Press; 2006:978-019.

20. Sim KA, Partridge SR, Sainsbury A. Does weight loss in overweight or obese women improve fertility treatment outcomes? A systematic review. Obes Rev 2014 Oct;15(10):839-850. [doi: 10.1111/obr.12217] [Medline: 25132280]

21. Legro RS, Dodson WC, Kunselman AR, Stetter CM, Kris-Etherton PM, Williams NI, et al. Benefit of Delayed Fertility Therapy With Preconception Weight Loss Over Immediate Therapy in Obese Women With PCOS. J Clin Endocrinol Metab 2016 Dec;101(7):2658-2666 [FREE Full text] [doi: 10.1210/jc.2016-1659] [Medline: 27172435]

22. van Oers AM, Mutsaerts MAQ, Burggraaff JM, Kuchenbecker WKH, Perquin DAM, Koks CAM, LIFEstyle study group. Cost-effectiveness analysis of lifestyle intervention in obese infertile women. Hum Reprod 2017 Dec 01;32(7):1418-1426. [doi: 10.1093/humrep/dex092] [Medline: 28486704]

23. Naberhuis J, Hunt VN, Bell JD, Partridge JR, Goates S, Nuijten MJC. Health care costs matter: a review of nutrition economics - is there a role for nutritional support to reduce the cost of medical health care? NDS 2017 Aug 01; Volume 9:55-62 [FREE Full text] [doi: 10.2147/nds.s126232]
Abbreviations
ICER: incremental cost-effectiveness ratio
IVF: in vitro fertilization
mHealth: mobile health
RCT: randomized controlled trial 
Edited by $G$ Eysenbach; submitted 06.03.19; peer-reviewed by $R$ Norman, A van Oers, D Rodger; comments to author 16.05.19; revised version received 29.06.19; accepted 28.07.19; published 23.10.19

Please cite as:

Oostingh EC, Ophuis RH, Koster MPH, Polinder S, Lingsma HF, Laven JSE, Steegers-Theunissen RPM

Mobile Health Coaching on Nutrition and Lifestyle Behaviors for Subfertile Couples Using the Smarter Pregnancy Program: Model-Based Cost-Effectiveness Analysis

JMIR Mhealth Uhealth 2019;7(10):e13935

URL: http://mhealth.jmir.org/2019/10/e13935/

doi: $\frac{10.2196 / 13935}{D: 31647476}$

PMID: $\underline{31647476}$

CElsje C Oostingh, Robbin H Ophuis, Maria PH Koster, Suzanne Polinder, Hester F Lingsma, Joop SE Laven, Régine PM Steegers-Theunissen. Originally published in JMIR Mhealth and Uhealth (http://mhealth.jmir.org), 23.10.2019. This is an open-access article distributed under the terms of the Creative Commons Attribution License (https://creativecommons.org/licenses/by/4.0/), which permits unrestricted use, distribution, and reproduction in any medium, provided the original work, first published in JMIR mhealth and uhealth, is properly cited. The complete bibliographic information, a link to the original publication on http://mhealth.jmir.org/, as well as this copyright and license information must be included. 